\title{
Periorbital Cellulitis Caused by Herpes Simplex Virus in a Child with Dedicator of Cytokinesis 8 Deficiency
}

\author{
Ambreen Pandrowala ${ }^{1} \cdot$ Parth Ganatra ${ }^{1} \cdot$ Minnie Bodhanwala ${ }^{2} \cdot$ Ajay Narayan Sharma ${ }^{1} \cdot$ Prashant Hiwarkar $^{1,3}$ (D)
}

Received: 21 August 2021 / Accepted: 11 January 2022/Published online: 22 February 2022

(c) Dr. K C Chaudhuri Foundation 2022

To the Editor: Dedicator of cytokinesis 8 deficiency (DOCK8 deficiency) was first described as a cause of primary immunodeficiency in 2009 in patients with severe eczema, cutaneous viral infections, and recurrent bacterial sinopulmonary infections $[1,2]$. Cutaneous viral infections in DOCK 8 deficiency can be severe and disseminated. We describe first child with DOCK8 deficiency and HSV periorbital cellulitis.

Our index case is a 1-y-6-mo-old boy who was referred for stem cell transplant. The child was found to harbor a homozygous 3' splice site variant in intron 16 of the DOCK8 gene (chr9:g.371427G $>$ T). During pretransplant evaluation, he presented with right-sided periorbital redness. A secondary staphylococcal infection was thought, and he was treated with amoxicillin-clavulanic acid. On day 3, the periorbital swelling worsened with mucoid eye discharge. As methicillin-resistant Staphylococcus aureus (MRSA) infection was a concern, he was started on intravenous teicoplanin. A swab of the eye discharge and an MRSA screening swab was sent. On day 3 of teicoplanin, the swelling worsened, involving the upper eye lid with inability to open the eye. We, therefore, considered nonbacterial causes of the periorbital cellulitis. The eye-swab culture was negative at $48 \mathrm{~h}$ and viral PCR of eye swab was positive for HSV-1. He was started on intravenous aciclovir. There was complete resolution of the periorbital swelling by day 3 of aciclovir.

DOCK8 is a member of DOCK superfamily of guanine nucleotide exchange factors which interact with Rho GTPase at the plasma membrane for spatial activation of $\mathrm{Cdc} 42$ in the dendritic cells [2]. Poor migration of $\mathrm{CD} 4+\mathrm{T}$ cells to the skin has been postulated to contribute to loss of control of HSV infection in DOCK8-deficient patients [3].

To summarize, HSV-1 may cause severe disease (including periorbital cellulitis) in patients with DOCK8 deficiency, and that this may mimic other entities, such as bacterial infection.

\section{Declarations}

Conflict of Interest None.

\section{References}

1. Engelhardt KR, McGhee S, Winkler S, et al. Large deletions and point mutations involving the dedicator of cytokinesis 8 (DOCK8) in the autosomal-recessive form of hyper-IgE syndrome. J Allergy Clin Immunol. 2009;124:1289-302.

2. Zhang Q, Davis JC, Lamborn IT, et al. Combined immunodeficiency associated with DOCK8 mutations. N Engl J Med. 2009;361:2046-55.

3. Flesch IE, Randall KL, Hollett NA, et al. Delayed control of herpes simplex virus infection and impaired CD4(+) T-cell migration to the skin in mouse models of DOCK8 deficiency. Immunol Cell Biol. 2015;93:517-21.

Publisher's Note Springer Nature remains neutral with regard to jurisdictional claims in published maps and institutional affiliations.

Prashant Hiwarkar

phiwarkar@nhs.net

1 Department of Blood and Marrow Transplantation, Bai Jerbai Wadia Hospital for Children, Mumbai, Maharashtra, India

2 Department of Pediatrics, Bai Jerbai Wadia Hospital for Children, Mumbai, Maharashtra, India

3 Department of Pediatric Hematology, Bai Jerbai Wadia Hospital for Children, Mumbai, Maharashtra 400012, India 